\title{
The role of transcriptional regulation in maintaining the availability of mycobacterial adenylate cyclases
}

Mycobacterium species have a complex cAMP regulatory network indicated by the high number of adenylate cyclases annotated in their genomes. However the need for a high level of redundancy in adenylate cyclase genes remains unknown. We have used semiquantitiative RT-PCR to examine the expression of eight Mycobacterium smegmatis cyclases with orthologs in the human pathogen Mycobacterium tuberculosis, where cAMP has recently been shown to be important for virulence. All eight cyclases were transcribed in all environments tested, and only four demonstrated environmental-mediated changes in transcription. M. smegmatis genes MSMEG_0545 and MSMEG_4279 were upregulated during starvation conditions while MSMEG_0545 and MSMEG_4924 were downregulated in $\mathrm{H}_{2} \mathrm{O}_{2}$ and MSMEG_3780 was downregulated in low $\mathrm{pH}$. Promoter fusion constructs

containing M. tuberculosis H37Rv promoters showed consistent regulation compared to their M. smegmatis orthologs. Overall our findings indicate that while low levels of transcriptional regulation occur, regulation at the mRNA level does not play a major role in controlling cellular cyclase availability in a given environment. 
1 Sarah J Casey ${ }^{2}$, Mica J. Ford ${ }^{1}$, and Michaela A. Gazdik ${ }^{1}$

$2{ }^{1}$ Biology Department, Ferrum College, Ferrum VA, 24088

$3{ }^{2}$ Department of Biomedical Sciences and Pathobiology, VA-MD Regional College of Veterinary

4 Medicine, Blacksburg, VA 24061

5 Corresponding Author:

6 Michaela Gazdik

780 Wiley Drive

8 Ferrum, VA 24088

9 540-365-4369

10 Email: mgazdik@,ferrum.edu

\section{Introduction}


13 adenylate cyclase enzymes which controls a wide range of cellular responses in both prokaryotic

14 and eukaryotic cells (Botsford \& Harman 1992; Peterkofsky et al. 1993; Tang \& Hurley 1998;

15 Baumann et al. 2007). cAMP signaling is critical for the regulation of virulence genes in several

16 bacterial pathogens such as Yersinia pestis and Pseudomonus aeruginosa, and recent evidence

17 suggests that cAMP also plays a role in the virulence of Mycobacterium tuberculosis, the

18 causative agent of tuberculosis (Rickman et al. 2005; Petersen \& Young 2002; Smith et al. 2004;

19 Agarwal et al. 2009). A bacterially-derived cAMP burst is responsible for increased levels of

20 cAMP in M. tuberculosis infected macrophages. The increased cAMP leads decreased

21 phagosome-lysosome fusion (Kalamidas et al. 2006) and increased production of CREB-

22 mediated TNF $\alpha$ (Agarwal et al. 2009). Both physiological responses aid in M. tuberculosis

23 survival after macrophage phagocytosis. Deletion of adenylate cyclase Rv0386 causes a loss of

24 the bacterial-derived intramacrophage cAMP, leading to decreased bacterial survival during

25 mouse infection (Agarwal et al. 2009). Additionally, deletion of the cAMP-controlled

26 transcription factor, cAMP Receptor Protein $\left(\mathrm{CRP}_{\mathrm{Mt}}\right)$, from the M. tuberculosis genome causes

27 attenuation of $M$. tuberculosis in a murine model and reduced bacterial growth rates in vitro and

28 within macrophages (Rickman et al. 2005; Akhter et al. 2008).

29 The classical model for cAMP regulation in bacteria is based on the well characterized

30 cAMP response in Escherichia coli (Botsford \& Harman 1992). E. coli contains a single class I

31 adenylate cyclase which catalyzes the conversion of ATP to cAMP (Peterkofsky et al. 1993). By

32 comparison, the M. tuberculosis $\mathrm{H} 37 \mathrm{Rv}$ genome contains 15 class III adenylate cyclases (McCue

33 et al. 2000), 10 of which have confirmed, biochemically distinct, activity (Castro et al. 2005;

34 Linder et al. 2004; Linder et al. 2002; Reddy et al. 2001; Abdel Motaal et al. 2006; Cann et al.

35 2003; Shenoy \& Visweswariah 2006; Guo et al. 2001; Sinha et al. 2005; Tews et al. 2005). 
36 Classes of adenylate cyclases contain separate, unrelated gene families with no structural

37 similarities. Class I cyclases are composed of cytoplasmic cyclases found in enterobacteria, class

38 II cyclases are secreted toxins, while class III is the largest and most diverse class. Class III

39 cyclases are typically multidomain proteins which include all of the known eukaryotic cyclases as

40 well as a variety of prokaryotic cyclases (Danchin 1993). M. tuberculosis class III cyclases

41 include receptor, membrane bound, and soluble type family members, and two (Rv1625c and

42 Rv2435c) belong to the mammalian type adenylyl cyclase grouping (McCue et al. 2000; Shenoy

43 \& Visweswariah 2006; Reddy et al. 2001). This abundance and diversity of adenylate cyclases

44 suggests a complex role for cAMP signaling in M. tuberculosis. Besides M. tuberculosis, other

45 mycobacterial species, including the nonpathogenic M. smegmatis, actinobacteria,

46 alphaproteobacteria, and cyanobacteria also contain a wide diversity of annotated class III

47 adenylate cyclases signifying that the $E$. coli paradigm is not transferrable to all bacterial species

48 (McCue et al. 2000; Shenoy et al. 2004).

With a high number of adenylate cyclases there is likely to be significant redundancy in mycobacterial cAMP production. Enzymatic regulation of adenylate cyclases in response to

51 changing environments has been identified as a regulatory mechanism in M. tuberculosis (Abdel

52 Motaal et al. 2006; Linder et al. 2004; Cann et al. 2003; Linder et al. 2002). However we

53 hypothesize that it is unlikely for all cyclases to be present in the cell at the same time. Instead, it

54 is more probable that cyclase regulation is first controlled at the level of transcription, with

55 expression dependent on specific environmental signals or growth stimuli. For instance, Dass et

56 al. (2008) demonstrated that expression of MSMEG_3780 is downregulated under low pH

57 conditions and that downregulation is tied to decreased production of cAMP in that environment

58 (Dass et al. 2008). While Dass et al., (2008) focused on characterizing the detailed regulation of

59 one cyclase we have examined expression of all eight $M$. tuberculosis cyclase orthologs found in 
nonpathogenic $M$. smegmatis to determine the role transcriptional regulation may have on the

61 availability of cyclases in the cell.

\section{Materials and Methods}

63 Bacterial culture

64 M. smegmatis mc $^{2} 155$ was grown in Tryptic Soy Broth (TSB) supplemented with 0.05\% Tween-

65 80. Cultures were grown in ambient air or $5 \% \mathrm{CO}_{2}$ at $37^{\circ} \mathrm{C}$ in $25 \mathrm{~cm}^{2}$ tissue culture flasks

66 rocking with gentle agitation. For gene regulation assays, late log phase cultures were exposed to

67 low $\mathrm{pH}$ (TSB adjusted to $\mathrm{pH} 5.5$ with $0.1 \mathrm{M} \mathrm{HCl}$ ), starvation (incubation in Phosphate Buffered

68 Saline), hydrogen peroxide $(5 \mathrm{mM})$, or nitric oxide (10 $\mathrm{mM}$ diethylenetriamine/nitric oxide

69 adduct) for 4 hours and gene expression was compared to non-exposed cultures.

\section{RNA preparation}

71 Late log phase culture of M. smegmatis $\mathrm{mc}^{2} 155$ was pelleted and resuspended in RNase-free

72 water. Cells were mechanically disrupted using a bead beater (BioSpec Products) for four rounds

73 of beating on high for 1 minute each, in a mixture of $0.1 \mathrm{~mm}$ zirconia-silica beads (BioSpec

74 Products) 45\% TRIzol (Invitrogen), 45\% acid phenol, and 10\% chloroform-isoamyl alcohol

75 (24:1). RNA was precipitated with isopropanol/3 M sodium acetate ( $\mathrm{pH}$ 5.2) and resuspended in

76 RNase-free water. RNeasy Mini Kit and RNase-free DNAse (Qiagen) were used to remove

77 contaminating DNA following manufacturer's specifications.

78 Semi-quantitative RT-PCR

79 cDNA was prepared from $0.5 \mu \mathrm{g}$ of RNA using the iScript cDNA synthesis kit according to the

80 manufacture's specifications (BioRad). PCR was run using a series of cDNA dilutions (0 -

81 1:1000) as templates to ensure reactions chosen for quantitation were in the linear range of the 
82 PCR (Table 1 for primers). Reactions were performed at $94^{\circ} \mathrm{C}$ for $1 \mathrm{~min}, 57^{\circ} \mathrm{C}$ for $1 \mathrm{~min}$ and $72^{\circ} \mathrm{C}$

83 for $1 \mathrm{~min}$ followed by a $10 \mathrm{~min}$ extension at $72^{\circ} \mathrm{C}$. Control reactions were performed against $16 \mathrm{~S}$

84 rDNA using cDNA diluted $10^{-5}$. PCR products were separated on agarose gels and band densities

85 quantified using ImageJ software (Abramoff et al. 2004). The 16S PCR products from all growth

86 conditions were normalized to one another before quantitation of individual genes, to ensure

87 equal levels of starting RNA in each reaction. 16S rDNA PCR was also performed using total

88 RNA without reverse transcription to ensure the absence of DNA contamination.

89 Gene reporter construction and assay

90 Promoter:gfp reporter strains were generated for gene expression analysis of $M$. tuberculosis

91 promoter regions in a M. smegmatis background. The intergeneic DNA sequences of the

92 adenylate cyclase genes were amplified by PCR (Table 1 for primer sequences) and amplified

93 DNA was cloned into pGFPoriM, which carries a promoterless gfpmut2 gene as previously

94 described (Purkayastha et al. 2002; Florczyk et al. 2003). Constructed plasmids were

95 electroporated into M. smegmatis $\mathrm{mc}^{2} 155$ at $2500 \mathrm{mV}$ (Eppendorf 2510 Electroporator). GFP

96 fluorescence from cultured cells was detected using GloMax Multi+ Detection System (Promega)

97 and normalized to $10^{6}$ bacteria based on $\mathrm{OD}_{600}$.

\section{Results and Discussion}

99 Regulation of $M$. smegmatis adenylate cyclases

100 The genome of M. smegmatis contains ten annotated adenylate cyclases, eight of which

101 have orthologs in pathogenic M. tuberculosis (Kapopoulou et al. 2011). In order to determine the

102 role of gene expression in adenylate cyclase availability we systematically examined transcription

103 of all eight orthologs using semi-quantitative RT-PCR. Gene expression was examined with a

104 focus on $M$. tuberculosis orthologs, using a variety of environments known to be relevant for $M$. 
105 tuberculosis infection. Conditions examined include starvation, low $\mathrm{pH}$, oxidative and nitrosative

106 stress and 5\% $\mathrm{CO}_{2}$. Evidence suggests that non-growing persistent $M$. tuberculosis is exposed to

107 nutrient starvation in lung granulomas (Betts et al. 2002; Nyka 1974) while low pH, oxidative

108 and nitrosative environments are known to occur following macrophage phagocytosis of $M$.

109 tuberculosis (Smith 2003; Liao et al. 2013; Chan et al. 1992).

110 Expression under control conditions (growth in TSB + Tween-80) indicated that all eight

111 adenylate cyclase genes are transcribed at the same time in the cell, albeit with varied levels of

112 transcription (Figure 1). Out of all conditions tested, starvation and oxidative stress $\left(\mathrm{H}_{2} \mathrm{O}_{2}\right.$

113 exposure) affect gene expression the most, with three genes showing statistically significant

114 changes in expression under starvation conditions and two demonstrating statistical changes in

115 expression under oxidative stress. This enhances the evidence of cAMP-mediated gene regulation

116 in nutrient-limiting conditions as $30 \%$ of the $M$. tuberculosis $\mathrm{CRP}_{\mathrm{Mt}}$ regulon has previously been

117 linked to nutrient starvation (Bai et al. 2005). Two genes (MSMEG_0545 and MSMEG_4279)

118 were upregulated 2-3 fold after 4 hrs of starvation while one gene (MSMEG_3780) was observed

119 to be downregulated approximately 2 fold after starvation and exposure to low $\mathrm{pH}$. Additionally,

120 two genes (MSMEG_0545 and MSMEG_4924) were downregulated approximately 2 fold under

121 oxidative stress (Figures 1 and 2). No expression differences were seen during nitrosative stress

122 or the presence of $\mathrm{CO}_{2}$ (data not shown).

123 Interestingly, the expression of only four of the eight adenylate cyclases was influenced

124 by the environments examined, and those observed expression changes, though significant, were

125 not dramatic. Combined with the result that all eight genes were transcribed at various levels in

126 all environments tested we conclude that our results counter our hypothesis and indicate that

127 transcriptional regulation plays only a minor role in controlling the availability of various

128 adenylate cyclases in the cell. Three of the four genes with environmentally-altered expression

129 encode for soluble adenylate cyclase proteins suggesting that transcriptional regulation may play 
130 a larger role in the availability of soluble cyclases as opposed to the membrane associated and

131 multi-domain structures. It is likely that biochemical regulation of various protein domains has

132 the dominant role in regulation of cAMP production by the redundant cyclases.

133 Regulation of M. tuberculosis adenylate cyclases

134 Of the ten annotated M. smegmatis cyclases, eight have reported orthologs in $M$.

135 tuberculosis and M. bovis, seven in M. marinum, and five in M. avium (Kapopoulou et al. 2011).

136 Phylogenic analysis based on protein sequence alignment was completed using Phylogeny.fr,

137 online software that combines MUSCLE for multiple alignment, PhyML for tree building, and

138 TreeDyn for tree rendering (Dereeper et al. 2008). This analysis confirmed the similarities of the

139 M. tuberculosis and M. smegmatis ortholgos (Figure 3). Additionally, promoter regions of each

140 ortholog pair, represented by the 500 nucleotides upstream of the putative ATG start site of each

141 gene, were compared for sequence similarities using the sequence alignment program T-Coffee

142 (Notredame et al. 2000; McWilliam et al. 2013). Percent identities ranged from 51.94\% to

$14382.08 \%$ (Table 2), indicating enough similarity to predict regulation would be similar between

144 orthologs.

145 In order to determine if regulation in M. smegmatis was similar to that of the pathogenic

146 orthologs we generated $g f p$ :promoter fusions using the intergenic regions amplified from H37Rv

147 chromosomal DNA. Overall, regulation between species orthologs was very similar. Rv1647

148 showed downregulation in both starvation and low pH similarly to MSMEG_3780, supporting

149 the observation by Dass et al (Dass et al. 2008) who reported comparable regulation (Figure 4).

150 Additionally, Rv1359 showed similar regulatory patterns of upregulation in starvation and

151 downregulation in oxidative stress as did MSMEG_0545 (Figure 4). Oxidative stress and

152 starvation are key environments for $M$. tuberculosis infection and latency respectively.

153 Interestingly, Rv1359 is one of five H37Rv annotated adenylate cyclases that has not been shown 
154 to be biochemically active. The catalytic mechanism of class III adenylate cyclases is predicted to

155 be a 2-metal ion reaction similar to DNA polymerase, where one metal ion, typically magnesium,

156 associates with ATP and the second is involved in the catalysis reaction (Zimmermann 1998). The

157 Rv1359 protein sequence contains a glycine residue in place of the first of two required metal

158 binding aspartates, along with missing a critical arginine residue, making it likely that this protein

159 cannot function as an enzymatically active homodimer (Shenoy et al. 2004). Blastp alignment of

160 the orthologs Rv1359 and MSMEG_0545 indicates that MSMEG_0545 is also missing the first

161 aspartate residue, containing an arginine in this location instead, suggesting that MSMEG_0545

162 may also be catalytically inactive.

163 Transcriptional regulation of Rv1359 and MSMEG_0545 suggests that these genes do

164 encode functional proteins. Guo et al. (2009) identified interactions between the Rv1359 protein

165 and the promoter regions of rubredoxin encoding genes $r u b \mathrm{~A}$ and $r u b \mathrm{~B}$ and fatty acid metabolic

166 genes $f a d \mathrm{D} 26, f a d \mathrm{E} 26$, and $f a d \mathrm{E} 27$ (Guo et al. 2009). These genes encode proteins that may

167 function in oxidative stress or starvation conditions. Rubredoxins are iron containing proteins

168 involved with electron transfer, which have been shown to be upregulated in phagocytized $M$.

169 tuberculosis (Buchko et al. 2011), an environment known to expose bacterial cells to oxidative

170 stress. FadD26 is a fatty acid synthetase that is downregulated during starvation of $M$.

171 tuberculosis (Betts et al. 2002) while FadE26 and FadE27 are involved in lipid degradation, a

172 process likely to be important for phagocytized mycobacteria which rely on fatty acids for

173 energy in the phagosome (Schnappinger et al. 2003). We hypothesize that Rv1359, and likely

174 MSMEG_0545, are transcriptional regulators which could play roles in mediating a cAMP signal

175 under oxidative stress and starvation. These proteins may function individually or in conjunction

176 with other proteins as $f a d \mathrm{D} 26$ has already been identified as part of the $\mathrm{CRP}_{\mathrm{Mt}}$ regulon (Rickman

177 et al. 2005). 
179 MSMEG_4924 and the Rv1320c promoter region. MSMEG_4924 has three predicted orthologs

180

181

182

183

184

185

186

187

188

189

190

191

192

193

194

195

196

197

198

199

in M. tuberculosis, Rv1318c, Rv1319c and Rv1320c. Rv1319c and Rv1320c comprise an operon

and are both represented by the Rv1320c promoter region. The regulatory similarity of

MSMEG_4924 to Rv1319c/Rv1320c and not Rv1318c correlates with the higher percent similarity to the promoter (82.08\%) compared to Rv1318c's promoter (54.6\%) (Table 2).

\section{Conclusions}

Mycobacterial species contain a high number of functional adenylate cyclases when compared to E. coli, the typical bacterial model system. The high level of cyclase redundancy led us to hypothesize that only specific cyclases would be expressed in the cell under any given condition. However, the results in this study counter that hypothesis, indicating that all $8 \mathrm{M}$. smegmatis cyclases are transcribed in the cell at one time. While cAMP has been shown to be important for M. tuberculosis pathogenesis, adenylate cyclase transcriptional regulation does not appear to have a major role in regulating the availability of cyclases in the cell. Observed changes in cyclase expression in response to varying environments was minor but statistical, and changes occurred under conditions physiologically relevant for M. tuberculosis infection. Additionally, regulation of expression was conserved between mycobacterial orthologs, validating the use of M. smegmatis as a model system for studying the complex mycobacterial adenylate cyclase/cAMP network.

\section{Acknowledgements}

We gratefully acknowledge Dr. Kathleen McDonough and Dr. Guanchun Bai for supplying the pGFPoriM vector used in our studies. 
201

202

203

204

205

206

207

208

209

210

211

212

213

214

215

216

217

218

219

220

221

222

223

224

225

226

227

228

229

230

231

232

233

234

235

236

237

238

239

240

241

242

243

244

245
Abdel Motaal, A., Tews, I., Schultz, J.E., Linder, J.U. \& Motaal, A.A., 2006. Fatty acid regulation of adenylyl cyclase Rv2212 from Mycobacterium tuberculosis H37Rv. The FEBS journal, 273, pp.4219-4228. Available at: http://eprints.soton.ac.uk/200621/ [Accessed August 23, 2013].

Abramoff, M., Megalhaes, P. \& Ram, S., 2004. Image Processing with ImageJ. Biophotonics International, 11(7), pp.36-42.

Agarwal, N., Lamichhane, G., Gupta, R., Nolan, S. \& Bishai, W.R., 2009. Cyclic AMP intoxication of macrophages by a Mycobacterium tuberculosis adenylate cyclase. Nature, 460(7251), pp.98-102. Available at: http://www.ncbi.nlm.nih.gov/entrez/query.fcgi? $\mathrm{cmd}=$ Retrieve $\& \mathrm{db}=$ PubMed\&dopt $=$ Citation\&list_uids $=19516256$.

Akhter, Y., Yellaboina, S., Farhana, A., Ranjan, A., Ahmed, N. \& Hasnain, S.E., 2008. Genome scale portrait of cAMP-receptor protein (CRP) regulons in mycobacteria points to their role in pathogenesis. Gene, 407(1-2), pp.148-158. Available at: http://www.ncbi.nlm.nih.gov/entrez/query.fcgi? $\mathrm{cmd}=$ Retrieve $\& \mathrm{db}=$ PubMed\&dopt $=$ Citation\&list_uids $=18022770$.

Bai, G., McCue, L.A. \& McDonough, K.A., 2005. Characterization of Mycobacterium tuberculosis Rv3676 (CRPMt), a cyclic AMP receptor protein-like DNA binding protein. Journal of bacteriology, 187(22), pp.7795-804. Available at: http://www.pubmedcentral.nih.gov/articlerender.fcgi? artid=1280308\&tool=pmcentrez\&rendertype=abstract [Accessed February 3, 2014].

Baumann, A., Lange, C. \& Soppa, J., 2007. Transcriptome changes and cAMP oscillations in an archaeal cell cycle. BMC cell biology, 8(1), p.21. Available at: http://www.biomedcentral.com/1471-2121/8/21 [Accessed February 2, 2014].

Betts, J.C., Lukey, P.T., Robb, L.C., McAdam, R.A. \& Duncan, K., 2002. Evaluation of a nutrient starvation model of Mycobacterium tuberculosis persistence by gene and protein expression profiling. Molecular microbiology, 43(3), pp.717-31. Available at: http://www.ncbi.nlm.nih.gov/pubmed/11929527 [Accessed May 30, 2013].

Botsford, J.L. \& Harman, J.G., 1992. Cyclic AMP in prokaryotes. Microbiol Rev, 56(1), pp.100122.

Buchko, G.W., Hewitt, S.N., Napuli, A.J., Van Voorhis, W.C. \& Myler, P.J., 2011. Solution-state NMR structure and biophysical characterization of zinc-substituted rubredoxin B (Rv3250c) from Mycobacterium tuberculosis. Acta crystallographica. Section F, Structural biology and crystallization communications, 67(Pt 9), pp.1148-53. Available at:

http://www.pubmedcentral.nih.gov/articlerender.fcgi? artid=3169417\&tool=pmcentrez\&rendertype=abstract [Accessed February 3, 2014].

Cann, M.J., Hammer, A., Zhou, J. \& Kanacher, T., 2003. A defined subset of adenylyl cyclases is regulated by bicarbonate ion. The Journal of biological chemistry, 278(37), pp.35033-8. Available at: http://www.ncbi.nlm.nih.gov/pubmed/12829712 [Accessed August 23, 2013 ].

Castro, L.I., Hermsen, C., Schultz, J.E. \& Linder, J.U., 2005. Adenylyl cyclase Rv0386 from Mycobacterium tuberculosis H37Rv uses a novel mode for substrate selection. Febs $J$, 272(12), pp.3085-3092. Available at: http://www.ncbi.nlm.nih.gov/entrez/query.fcgi? $\mathrm{cmd}=$ Retrieve $\& \mathrm{db}=$ PubMed\&dopt $=$ Citation\&list_uids $=15955067$.

Chan, J., Xing, Y., Magliozzo, R.S. \& Bloom, B.R., 1992. Killing of virulent Mycobacterium tuberculosis by reactive nitrogen intermediates produced by activated murine macrophages. The Journal of experimental medicine, 175(4), pp.1111-22. Available at: 
http://www.pubmedcentral.nih.gov/articlerender.fcgi?

artid=2119182\&tool=pmcentrez\&rendertype=abstract [Accessed February 7, 2014].

Danchin, A., 1993. Phylogeny of adenylyl cyclases. Advances in second messenger and phosphoprotein research, 27, pp.109-62. Available at: http://www.ncbi.nlm.nih.gov/pubmed/8418825 [Accessed February 2, 2014].

Dass, B.K., Sharma, R., Shenoy, A.R., Mattoo, R. \& Visweswariah, S.S., 2008. Cyclic AMP in mycobacteria: characterization and functional role of the Rv1647 ortholog in Mycobacterium smegmatis. J Bacteriol, 190(11), pp.3824-3834. Available at: http://www.ncbi.nlm.nih.gov/entrez/query.fcgi? $\mathrm{cmd}=$ Retrieve $\& \mathrm{db}=$ PubMed\&dopt $=$ Citation\&list_uids $=18390660$.

Dereeper, A. et al., 2008. Phylogeny.fr: robust phylogenetic analysis for the non-specialist. Nucleic acids research, 36(Web Server issue), pp.W465-9. Available at: http://www.pubmedcentral.nih.gov/articlerender.fcgi? artid=2447785\&tool=pmcentrez\&rendertype=abstract [Accessed January 30, 2014].

Florczyk, M.A., McCue, L.A., Purkayastha, A., Currenti, E., Wolin, M.J. \& McDonough, K.A., 2003. A family of acr-coregulated Mycobacterium tuberculosis genes shares a common DNA motif and requires Rv3133c (dosR or devR) for expression. Infection and immunity, 71(9), pp.5332-43. Available at: http://www.pubmedcentral.nih.gov/articlerender.fcgi? artid=187371\&tool=pmcentrez\&rendertype=abstract [Accessed September 17, 2013].

Guo, M., Feng, H., Zhang, J., Wang, W., Wang, Y., Li, Y., Gao, C., Chen, H., Feng, Y. \& He, Z.G., 2009. Dissecting transcription regulatory pathways through a new bacterial one-hybrid reporter system. Genome research, 19(7), pp.1301-8. Available at:

http://www.pubmedcentral.nih.gov/articlerender.fcgi? artid=2704442\&tool=pmcentrez\&rendertype=abstract [Accessed January 29, 2014].

Guo, Y.L., Seebacher, T., Kurz, U., Linder, J.U. \& Schultz, J.E., 2001. Adenylyl cyclase Rv1625c of Mycobacterium tuberculosis: a progenitor of mammalian adenylyl cyclases. EMBO J, 20(14), pp.3667-3675.

Kalamidas, S.A., Kuehnel, M.P., Peyron, P., Rybin, V., Rauch, S., Kotoulas, O.B., Houslay, M. Hemmings, B.A., Gutierrez, M.G., Anes, E., \& Griffiths, G., 2006. cAMP synthesis and degradation by phagosomes regulate actin assembly and fusion events: consequences for mycobacteria. J Cell Sci, 119(Pt 17), pp.3686-3694. Available at: http://www.ncbi.nlm.nih.gov/entrez/query.fcgi? $\mathrm{cmd}=$ Retrieve $\& \mathrm{db}=$ PubMed\&dopt $=$ Citation\&list_uids $=16931599$.

Kapopoulou, A., Lew, J.M. \& Cole, S.T., 2011. The MycoBrowser portal: a comprehensive and manually annotated resource for mycobacterial genomes. Tuberculosis (Edinb), 91(1), pp.813. Available at: http://www.ncbi.nlm.nih.gov/entrez/query.fcgi? $\mathrm{cmd}=$ Retrieve $\& \mathrm{db}=$ PubMed\&dopt $=$ Citation\&list_uids $=20980200$.

Liao, D., Fan, Q. \& Bao, L., 2013. The role of superoxide dismutase in the survival of Mycobacterium tuberculosis in macrophages. Japanese journal of infectious diseases, 66(6), pp.480-8. Available at: http://www.ncbi.nlm.nih.gov/pubmed/24270134 [Accessed February 7, 2014].

Linder, J.U., Hammer, A. \& Schultz, J.E., 2004. The effect of HAMP domains on class IIIb adenylyl cyclases from Mycobacterium tuberculosis. Eur J Biochem, 271(12), pp.24462451. Available at: http://www.ncbi.nlm.nih.gov/entrez/query.fcgi? $\mathrm{cmd}=$ Retrieve $\& \mathrm{db}=$ PubMed\&dopt $=$ Citation\&list_uids $=15182360$.

Linder, J.U., Schultz, A. \& Schultz, J.E., 2002. Adenylyl cyclase Rv1264 from Mycobacterium tuberculosis has an autoinhibitory N-terminal domain. J Biol Chem, 277(18), pp.15271- 
15276. Available at: http://www.ncbi.nlm.nih.gov/entrez/query.fcgi? $\mathrm{cmd}=$ Retrieve $\& \mathrm{db}=$ PubMed\&dopt $=$ Citation\&list_uids $=11839758$.

McCue, L.A., McDonough, K.A. \& Lawrence, C.E., 2000. Functional classification of cNMPbinding proteins and nucleotide cyclases with implications for novel regulatory pathways in Mycobacterium tuberculosis. Genome Res, 10(2), pp.204-219.

McWilliam, H., Li, W., Uludag, M., Squizzato, S., Park, Y.M., Buso, N., Cowley, A.P. \& Lopez, R., 2013. Analysis Tool Web Services from the EMBL-EBI. Nucleic acids research, 41(Web Server issue), pp.W597-600. Available at: http://europepmc.org/articles/PMC3692137 [Accessed January 30, 2014].

Notredame, C., Higgins, D.G. \& Heringa, J., 2000. T-Coffee: A novel method for fast and accurate multiple sequence alignment. Journal of Molecular Biology, 302(1), pp.205-217.

Nyka, W., 1974. Studies on the effect of starvation on mycobacteria. Infection and immunity, 9(5), pp.843-50. Available at: http://www.pubmedcentral.nih.gov/articlerender.fcgi? artid $=414896 \&$ tool $=$ pmcentrez\&rendertype $=$ abstract [Accessed February 3, 2014].

Peterkofsky, A., Reizer, A., Reizer, J., Gollop, N., Zhu, P.P. \& Amin, N., 1993. Bacterial adenylyl cyclases. Prog Nucleic Acid Res Mol Biol, 44, pp.31-65.

Petersen, S. \& Young, G.M., 2002. Essential role for cyclic AMP and its receptor protein in Yersinia enterocolitica virulence. Infect Immun, 70(7), pp.3665-3672.

Purkayastha, A., McCue, L.A. \& McDonough, K.A., 2002. Identification of a Mycobacterium tuberculosis putative classical nitroreductase gene whose expression is coregulated with that of the acr aene within macrophages, in standing versus shaking cultures, and under low oxygen conditions. Infection and immunity, 70(3), pp.1518-29. Available at: http://www.pubmedcentral.nih.gov/articlerender.fcgi? artid $=127740 \&$ tool $=$ pmcentrez\&rendertype $=$ abstract [Accessed September 17, 2013].

Reddy, S.K., Kamireddi, M., Dhanireddy, K., Young, L., Davis, A. \& Reddy, P.T., 2001. Eukaryotic-like adenylyl cyclases in Mycobacterium tuberculosis H37Rv: cloning and characterization. J Biol Chem, 276(37), pp.35141-35149. Available at: http://www.ncbi.nlm.nih.gov/entrez/query.fcgi? $\mathrm{cmd}=$ Retrieve $\& \mathrm{db}=$ PubMed\&dopt $=$ Citation\&list_uids $=11431477$.

Rickman, L., Scott, C., Hunt, D.M., Hutchinson, T., Menendez, M.C., Whalan, R., Hinds, J., Colston, M.J., Green, J. \& Buxton, R.S., 2005. A member of the cAMP receptor protein family of transcription regulators in Mycobacterium tuberculosis is required for virulence in mice and controls transcription of the rpfA gene coding for a resuscitation promoting factor. Mol Microbiol, 56(5), pp.1274-1286. Available at: http://www.ncbi.nlm.nih.gov/entrez/query.fcgi? $\mathrm{cmd}=$ Retrieve $\& \mathrm{db}=$ PubMed\&dopt $=$ Citation\&list_uids $=15882420$.

Schnappinger, D., Ehrt, S., Voskuil M.I., Liu, Y., Mangan, J.A., Monahan, I.M., Dolganov, G., Efron, B., Butcher, P.D., Nathan, C., \& Schoolnik G.K., 2003. Transcriptional Adaptation of Mycobacterium tuberculosis within Macrophages: Insights into the Phagosomal Environment. The Journal of experimental medicine, 198(5), pp.693-704. Available at: http://www.pubmedcentral.nih.gov/articlerender.fcgi? artid $=2194186 \&$ tool $=$ pmcentrez\&rendertype $=$ abstract [Accessed August 9, 2013].

Shenoy, A.R., Sivakumar, K., Krupa, A., Srinivasan, N. \& Visweswariah, S.S., 2004. A survey of nucleotide cyclases in actinobacteria: unique domain organization and expansion of the class III cyclase family in Mycobacterium tuberculosis. Comparative and functional genomics, 5(1), pp.17-38. Available at: http://www.pubmedcentral.nih.gov/articlerender.fcgi? artid $=2447327 \&$ tool $=$ pmcentrez\&rendertype $=$ abstract [Accessed August 24, 2013] . 
340

341

342

343

344

345

346

347

348

349

350

351

352

353

354

355

356

357

358

359

360

361
Shenoy, A.R. \& Visweswariah, S.S., 2006. Mycobacterial adenylyl cyclases: biochemical diversity and structural plasticity. FEBS Lett, 580(14), pp.3344-3352. Available at: http://www.ncbi.nlm.nih.gov/entrez/query.fcgi? $\mathrm{cmd}=$ Retrieve $\& \mathrm{db}=$ PubMed\&dopt $=$ Citation\&list_uids $=16730005$.

Sinha, S.C., Wetterer, M., Sprang, S.R., Schultz, J.E. \& Linder, J.U., 2005. Origin of asymmetry in adenylyl cyclases: structures of Mycobacterium tuberculosis Rv1900c. EMBO J, 24(4), pp.663-673.

Smith, I., 2003. Mycobacterium tuberculosis pathogenesis and molecular determinants of virulence. Clinical Microbiology Reviews, 16(3), pp.463-496. Available at: http://cmr.asm.org/cgi/content/long/16/3/463 [Accessed May 24, 2013].

Smith, R.S., Wolfgang, M.C. \& Lory, S., 2004. An adenylate cyclase-controlled signaling network regulates Pseudomonas aeruginosa virulence in a mouse model of acute pneumonia. Infect Immun, 72, pp.1677-1684.

Tang, W.J. \& Hurley, J.H., 1998. Catalytic mechanism and regulation of mammalian adenylyl cyclases. Mol Pharm, 54, pp.231-240.

Tews, I., Findeisen, F., Sinning, I., Schultz, A., Schultz, J.E. \& Linder, J.U., 2005. The structure of a pH-sensing mycobacterial adenylyl cyclase holoenzyme. Science, 308(5724), pp.10201023.

Zimmermann, G., 1998. Mutations Uncover a Role for Two Magnesium Ions in the Catalytic Mechanism of Adenylyl Cyclase. Journal of Biological Chemistry, 273(31), pp.1965019655. Available at: http://www.jbc.org/content/273/31/19650.long [Accessed February 2, 2014]. 


\section{Table 1 (on next page)}

Primers used throughout this study 
RT-PCR

\begin{tabular}{|c|c|c|c|}
\hline Gene & Sequence $^{a}$ & Gene & Sequence \\
\hline \multirow[t]{2}{*}{ MSMEG_0545 } & F-GATCGAGCCGAAGAACTGTG & Rv1264 & F-NNNNGGATCCGACGATGTCGACGTAGTTGT \\
\hline & R-ATTGAGGGCGATCAAGTGAG & & R-NNNNGGTACCGCGCACGTGGTCTGTCAC \\
\hline \multirow[t]{2}{*}{ MSMEG_3578 } & F-CGATCGTCAACAAACTGGTG & Rv1318c & F-NNNNGGATCCAGATGCCCGAGGTCCAAG \\
\hline & R-CAGGTATCCGTTGTGCAGTG & & R-NNNNGGTACCGTGCTCTTGGCCGACAT \\
\hline \multirow[t]{2}{*}{ MSMEG_3780 } & F-CATACTCTTGCGCCTGTGAA & Rv1319c & F-NNNNGGTACCCGATCGCGGTCATGTACTC \\
\hline & R-CCCTGAGGTCTTTCGTGCT & & R-NNNNGGTACCTGTGTCGGTCACGCTCTAAG \\
\hline \multirow[t]{2}{*}{ MSMEG_4279 } & F-CGACCTGTCGGATTTCACC & Rv1359 & F-NNNNGGATCCGGAGGTTCGCCACAAGATT \\
\hline & R-CATCTGATGCCGCAGAACT & & R-NNNNGGTACCCGATACCTTCCGGCTAAGCA \\
\hline \multirow[t]{2}{*}{ MSMEG_4477 } & F-AGCCTGGCGTATCAGCTCT & Rv1647 & F-NNNNGGATCCAGCGGGAACCGCTAGGG \\
\hline & R- ACGGTCCAGAACAATTCGAC & & R-NNNNGGTACCGTAGGTGGTGCGGGCTGAG \\
\hline \multirow[t]{2}{*}{ MSMEG_4924 } & F-GTGACGCTGGAGAACCTGAC & Rv1900c & F-NNNNGGATCCACCGGATCGATCACTTGC \\
\hline & R-AAGATGAAGCCGAACACCAG & & R-NNNNGGTACCATGGTCGAGGCGGATCAC \\
\hline \multirow[t]{2}{*}{ MSMEG_5018 } & F-ATCCAGCCACTCCTGGAAG & Rv2212 & F-NNNNGGATCCGCAGATTGGTGATGCTCAGA \\
\hline & R-TGAGCAGCCAGTTGATCAGT & & R-NNNNGGTACCGACCATAGCAGGACGTCACC \\
\hline \multirow[t]{2}{*}{ MSMEG_6154 } & F-CCTGCTCAACGAGTTCTTCC & Rv2435c & F-NNNNGGATCCGTCTGAGTGCGTCGTCGTT \\
\hline & R-GCGTCACCCTGGAACTTGT & & R-NNNNGGTACCTACCGAGTCCAGTGCCTCAC \\
\hline \multirow[t]{2}{*}{ 16S rDNA } & F-GCGATACGGGCAGACTAGAG & Rv3645 & F-NNNNGGATCCAATCACCACGATCTGCCAGT \\
\hline & R-ССTCCTCCTGATATCTGCGCATT & & R-NNNNGGTACCGCATGCTCAGCGAGAACAG \\
\hline \multirow[t]{2}{*}{$\operatorname{sig} \mathrm{A}$} & F-TCGAGGACGAGGAAGAAGAA & tuf & F-NNNNGGATCCGTGCGGAAGTAGAACTGCGG \\
\hline & R-CCTCCAGCAGATGGTTTTTG & & R-NNNNGGTACCAGGAAGTTGAGATCGTCGGC \\
\hline
\end{tabular}

${ }^{\mathrm{a}} \mathrm{F}$ - forward primer, $\mathrm{R}$ - reverse primer

NNNN - added nucleotides to aid in restriction digestion, sequence irrelevant 


\section{Figure 1}

Regulation of M. smegmatis adenylate cyclase genes under starvation conditions

Semi-quantitative RT-PCR was used to compare adenylate cyclase mRNA levels between late-log phase cultures incubated for 4 hours in mycomedia (control) or PBS (starvation). (A) A representative depiction of PCR-amplified cDNA separated using agarose gel electrophoresis. (B) Quantification of control (black bars) and starvation (white bars) PCR products depicted in A. (C) Average of three different experiments represented as fold differences of starvation compared to control expression. * indicates statistically significant difference between expression in control and starvation for an individual gene $(P<0.05)$

A

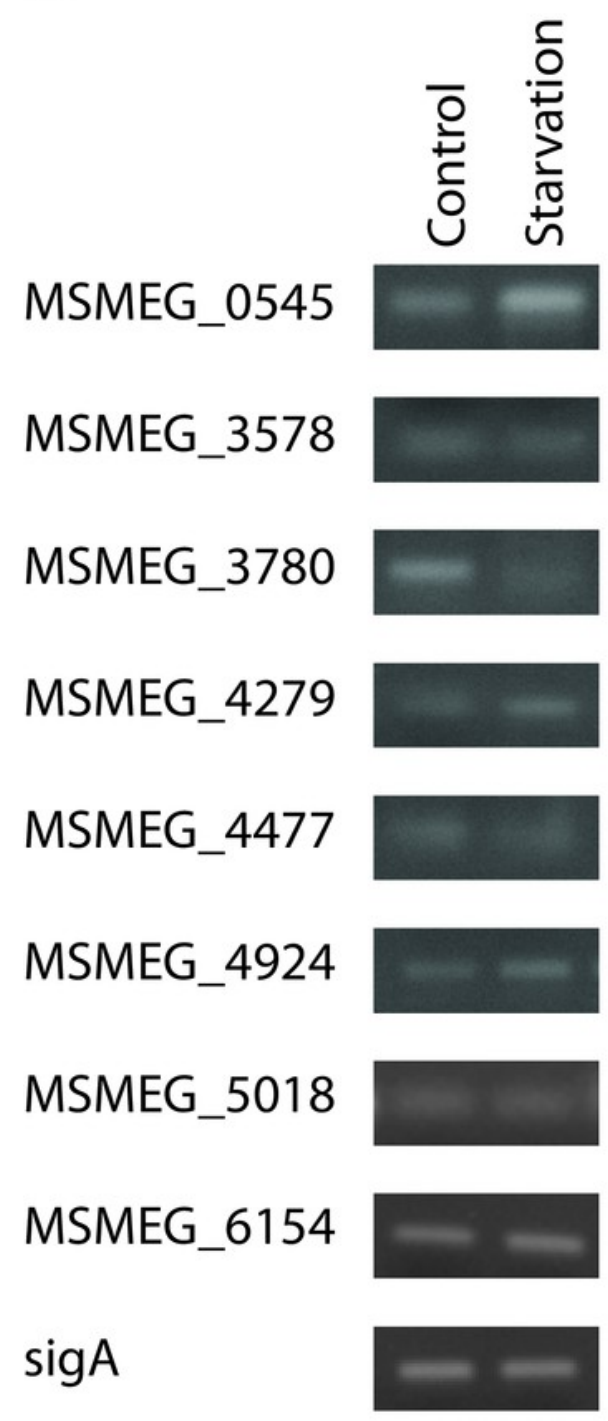

B

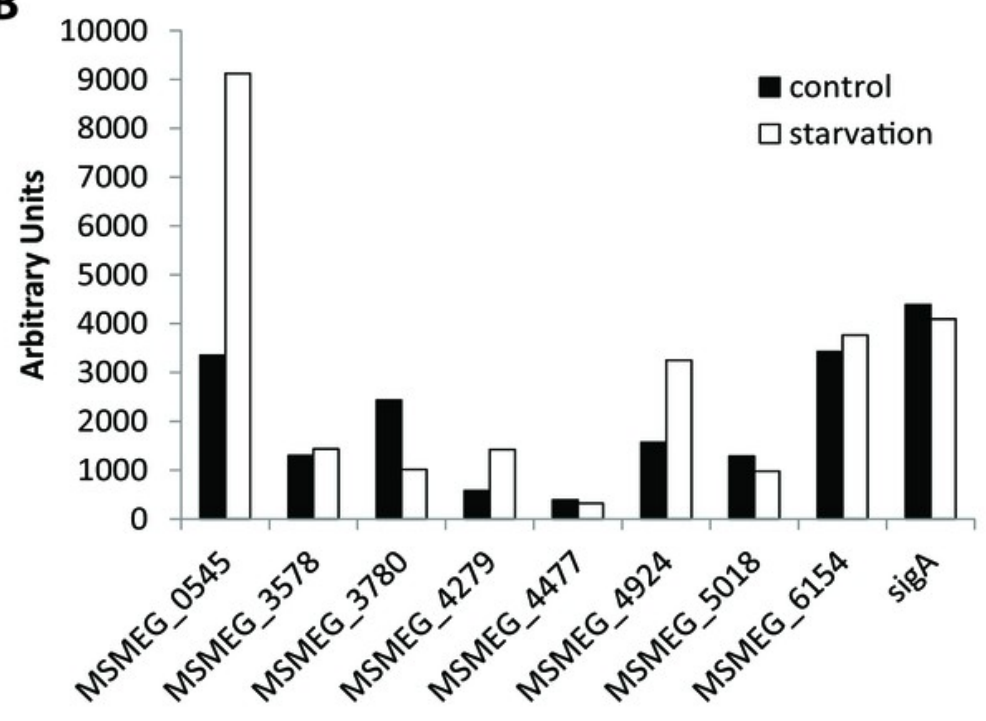

C

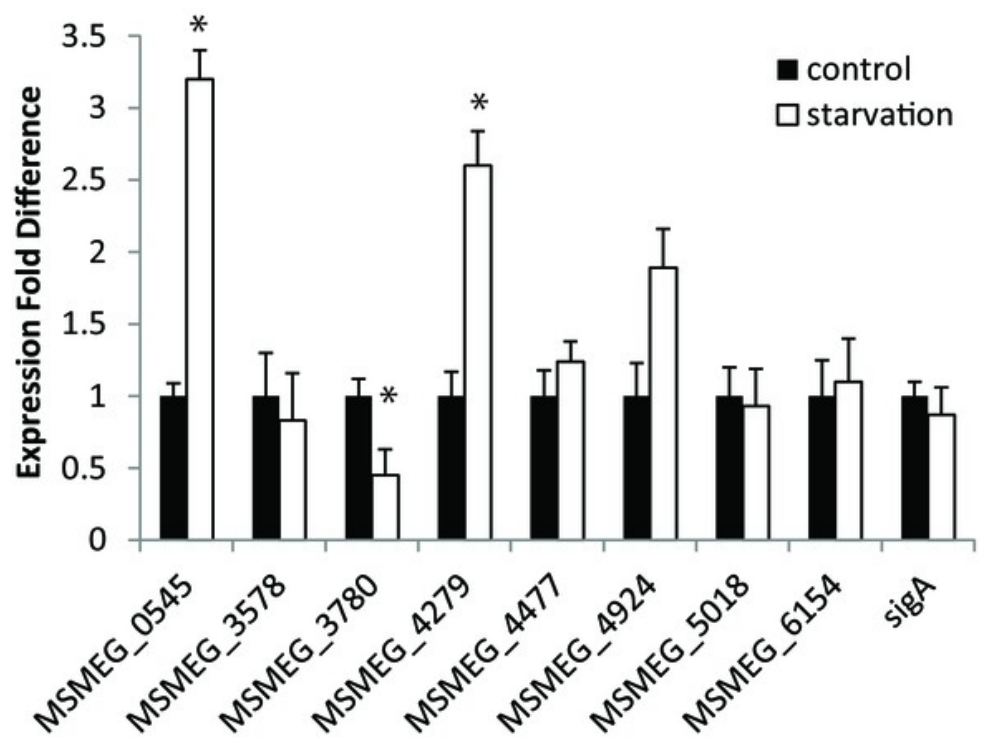




\section{Figure 2}

Regulation of $M$. smegmatis adenylate cyclase genes under low $\mathrm{pH}$ and oxidative stress

Semi-quantitative RT-PCR was used to compare adenylate cyclase mRNA levels between late-log phase cultures incubated for 4 hours in mycomedia (control, black bars), mycomedia adjusted to $\mathrm{pH} 5.5$ (low $\mathrm{pH}$, hatched bars), and mycomedia containing $\mathrm{H}_{2} \mathrm{O}_{2}\left(\mathrm{H}_{2} \mathrm{O}_{2}\right.$, grey bars). Results are the average of three independent experiments and are expressed in fold difference comparing experimental condition to control. * indicates conditions with statistically significant differences in expression compared to control for an individual gene $(P<0.05)$ 


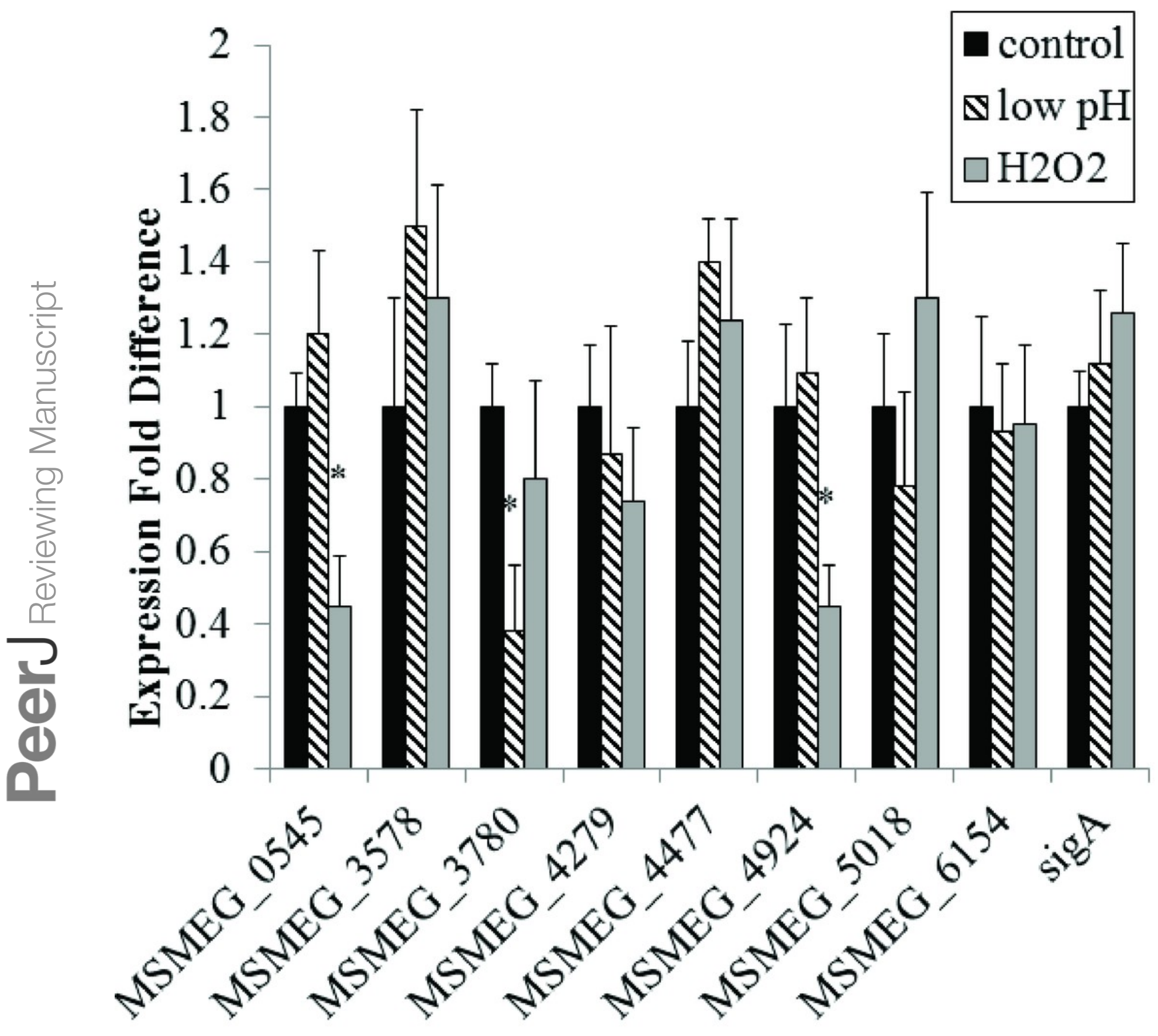




\section{Figure 3}

Phylogenic analysis of $M$. tuberculosis and $M$. smegmatis adenylate cyclase orthologs

Amino acid sequences obtain from MycoBrowser databases were aligned and used to generate a phylogenic tree using Phylogeny.fr, combining alignment with MUSCLE, tree building with PhyML, and TreeDyn for tree rendering. The percentage of replicate trees in which the associated orthologs clustered together in the bootstrap test is shown above the horizontal branches. The branch lengths are drawn to represent evolutionary distances.

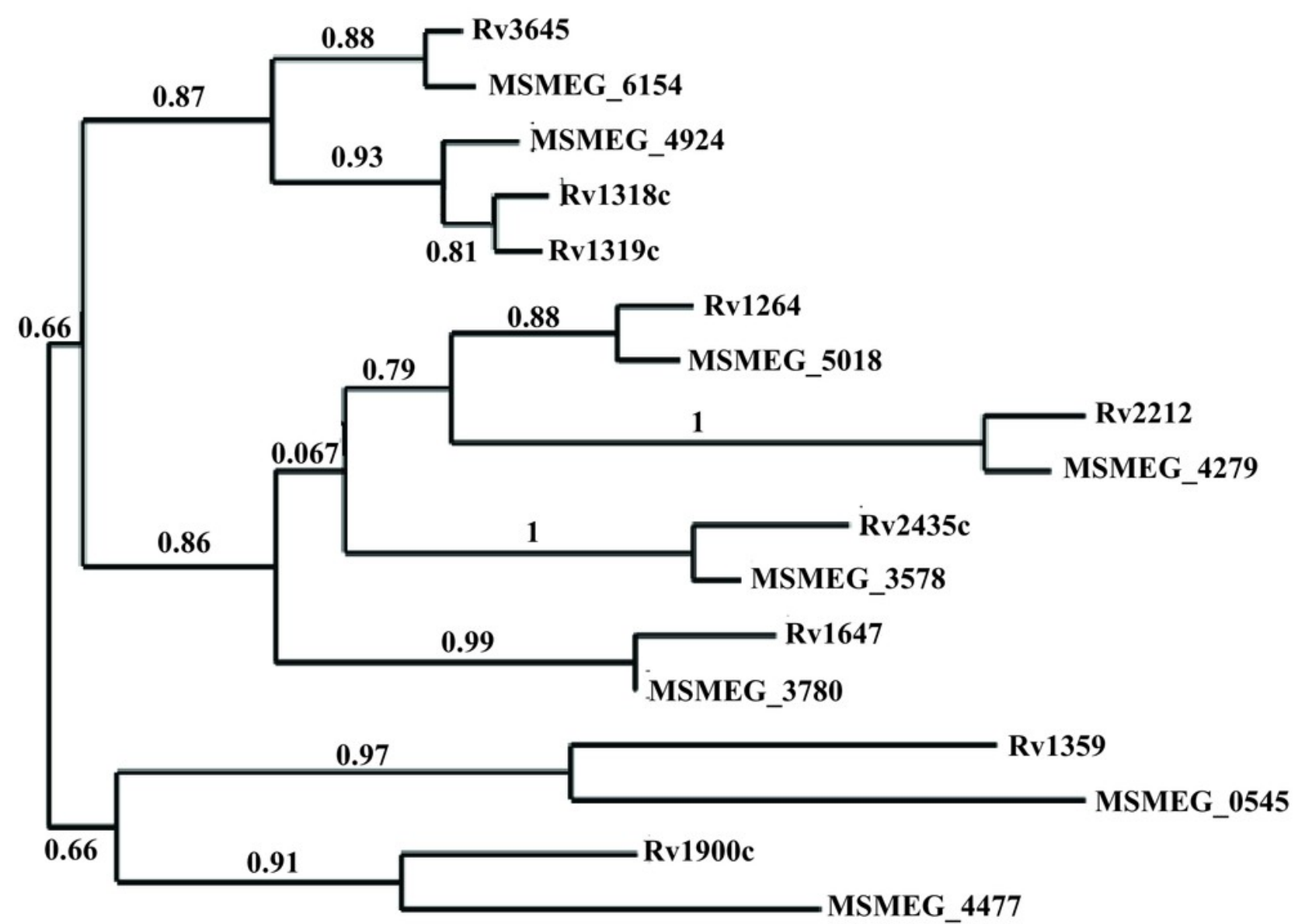

0.8 


\section{Table 2 (on next page)}

Percent identity between Mtb and M. smegmatis ortholog promoters ${ }^{\mathrm{a}}$ 


\begin{tabular}{|c|c|c|}
\hline $\begin{array}{l}\text { MSME } \\
\text { G gene }\end{array}$ & $\begin{array}{c}\text { H37Rv } \\
\text { gene }\end{array}$ & $\begin{array}{l}\text { Percent } \\
\text { Identity }^{b}\end{array}$ \\
\hline 0545 & Rv1359 & 57.02 \\
\hline 3578 & Rv2435 & 46.3 \\
\hline 3780 & Rv1647 & 51.94 \\
\hline 4279 & Rv2212 & 78.97 \\
\hline 4477 & Rv1900 & 54.42 \\
\hline 4924 & Rv1318c & 54.6 \\
\hline 4924 & $\begin{array}{l}\text { Rv1319c/ } \\
\text { Rv1320c }\end{array}$ & 82.08 \\
\hline 5018 & Rv1264 & 54.01 \\
\hline 6154 & Rv2645 & 69.28 \\
\hline
\end{tabular}

${ }^{\text {a }}$ Promoter region defined as the 500 nucleotides upstream of translation start site

${ }^{\mathrm{b}}$ Determined with T-Coffee multi-sequence alignment 


\section{Figure 4}

Regulation of $M$. tuberculosis adenylate cyclase genes

GFP: promoter fusions containing $M$. tuberculosis promoters were electroporated into $M$. smegmatis and used to examine adenylate cyclase expression in late log phase cultures after 4 hour incubation in mycomedia (control, black bar), PBS (starvation, white bar), mycomedia adjusted to $\mathrm{pH} 5.5$ (low pH, hatched bars), and mycomedia containing $\mathrm{H}_{2} \mathrm{O}_{2}$ $\left(\mathrm{H}_{2} \mathrm{O}_{2}\right.$, grey bars). Fluorescence was normalized to $10^{6}$ cells and represented as the average of three independent experiments. ${ }^{*}$ indicates conditions with statistically significant differences in expression compared to control for an individual gene $(P<0.05)$

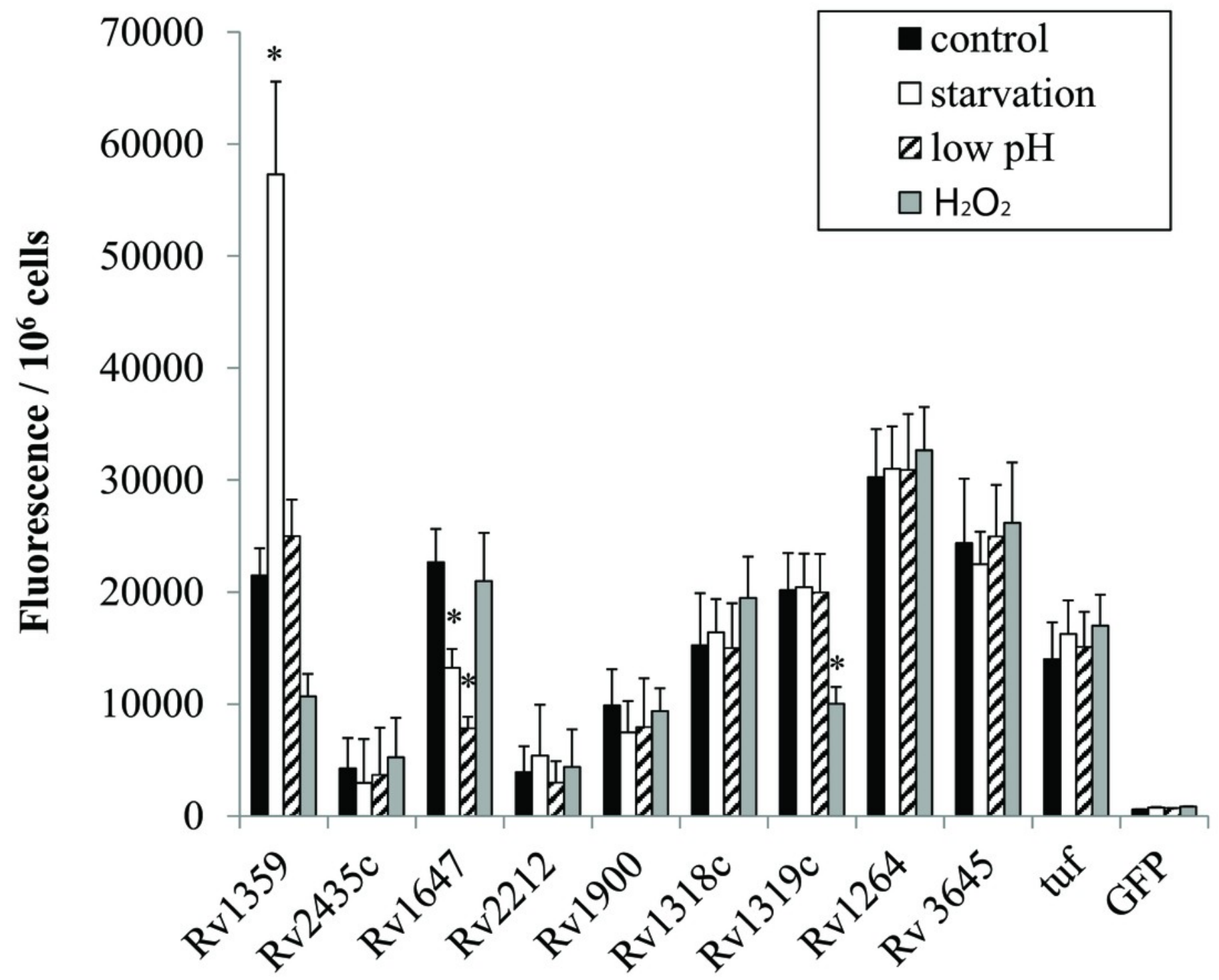

